\title{
Research on Development Innovation Shape of Low Carbon Insurance in Urban and Rural Areas
}

\author{
Si-yun $\mathrm{Xu}^{1,2}$, Ruihua-Hu ${ }^{3}$ \\ ${ }^{1}$ Department of Insurance, Hebei Finance University, Baoding, China \\ ${ }^{2}$ School of Insurance and Economics, University of International Business and Economics, Beijing, China \\ ${ }^{3}$ Hebei Finance University, Baoding, China
}

\begin{abstract}
Low carbon environmental protection has become the basic requirement of nowadays development, each big commercial Banks also try to explore in the field of low carbon finance, research and development of new products. Low carbon insurance has the development. As an agricultural country in our country, urban and rural low carbon rural insurance market prospect. Government departments should attach great importance to guarantee the farmers' interests, and the insurance company. Insurance companies should try to innovation, cater to urban and rural markets, and promote urban and rural development of low carbon insurance.
\end{abstract}

Keywords: Low Carbon Insurance; Urban and Rural markets; Innovation Mode

\section{Introduction}

Low carbon environmental protection, the concept of scientific development swept across all over the world, the financial sector has become one of them. As an important channel of financial sector funds circulation each big commercial Banks will also explore the direction of the on the low carbon financial. Insurance as the social stability and favorable protection and promoting force of sustainable development, and also need accordingly on low carbon development in the field of financial contribution, assumes the social responsibility. Thus infer, low carbon insurance market prospect is considerable.

In terms of our country, it is an agricultural country. Agriculture is the important pillar of the national survival and development power. Now, all across the country in advocate energy saving, low carbon, low carbon life, but for the direction of the urban and rural areas agricultural value is low carbon economy. As an agricultural country in the world, China's population density is big, the agricultural population than major, for better development, focus on low carbon insurance to promote the development of urban and rural areas is imminent.

For better study, this article selects agricultural big province, Jiangsu province, as the research object, the research analysis and research.

\section{The present situation of the development of urban and rural insurance market}

Our country agricultural country for years, on the one hand, urban and rural farming population, by 2010, the national rural agricultural population proportion is about $43 \%$. On the other hand, the imbalance of urban and rural economic development in our country, many urban areas per capita national income gap is quite big. Based on this, the implementation of the central party committee called for, and actively to strengthen urban and rural insurance of low carbon propaganda, improve farmers' insurance awareness is particularly important. To better promote the development of low carbon insurance, in the first discusses some successful root in urban and rural areas of coverage and insurance mode. 


\subsection{Agricultural Insurance Mode}

In 2007, the state has chosen six provinces across the country as a pilot "policy-oriented agricultural insurance". It has been seven years. Through seven years of exploration, innovation, and various provinces out of the business model with local unique characteristics. For example, Jiangsu province agricultural insurance is the top in the country. Its premium income had nearly 2 billion Yuan, was nearly one over ten of the total number of the country. Agricultural insurance also provides the ginseng protect farmers in Jiangsu province agricultural risk guarantee is as high as about 30 billion Yuan.

So gratifying results, is closely related with the agricultural insurance policy of Jiangsu province, coverage, coverage and all, should be guaranteed that all has been basically achieved.

\subsection{Social Endowment Insurance and Medical Insurance in Urban and Rural}

Through the 2002, our country started the new-pattern rural social old-age insurance and promoted pilot implementation of the plan. As one of the earliest pilot provinces of the nation's outstanding achievements, that is the Jiangsu province, is worth in-depth study. On December 29, 2009, Jiangsu province social endowment insurance system of the relevant implementation measures shall be formally launched. This specification document has been clear about the new farming maintain full cover of working-age residents, and fund raising and government subsidies of details such as specified. A year later, the number of the contributors in Jiangsu province was the most in the nation. New-pattern rural social old-age insurance is a certain extent to guarantee the basic life of farmers. For realizing the comprehensive well-off in 2020 , it is a big role.

\section{The Necessity of the Development in Urban and Rural Insurance Market}

\subsection{The Relatively Serious Environmental Pollution in Urban and Rural}

"Three wastes", the daily life and waste agricultural drug fertilizer is the main source of environmental pollution in rural areas in China. As the country "policy-oriented agricultural insurance" to further promote and implement, extensive farming pattern and way of life has a certain improvement. But, the rubbish pollution and optionally, throwing away phenomenon is still widespread. From the results of the questionnaire survey and statistical data of related departments, the urban and rural environmental pollution problem is still serious.

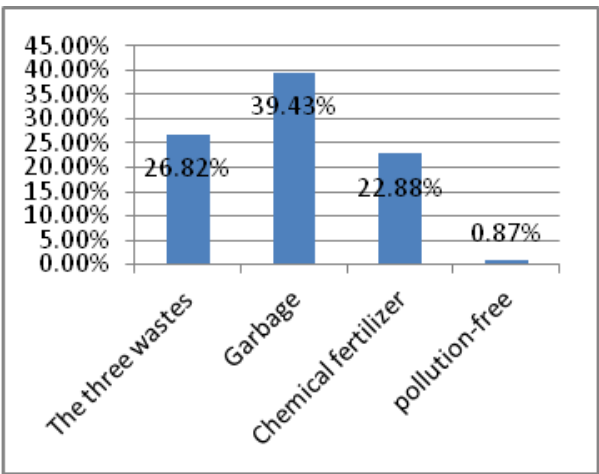

Fig.1 The distribution of major pollution sources

\subsection{Inadequate protection of the urban and rural endowment insurance}

In ancient times, our country has the tradition of rearing sons for help in old age. But as more and more young adult labors choose go out to work, not do simple farming at home. Family structure and the number of members gradually has become toward miniaturization. Traditional way, that the grown up children support their own parents, have been unable to adapt to our country urban and rural, the realistic basic demand for pension now.

In addition, for the present, social endowment institutions generally there is a serious waste of resources. $45.78 \%$ of endowment institutions exist behind the condition of the facilities. Pension institutions, $19.01 \%$ of sites scattered, 
small in size, unable to integrate resources to make full use of the well. More than $16 \%$ of the endowment institutions financing source is not stable.

Since the state adopts the system of new agricultural insurance, all over the country provinces and regions to realizing a complete coverage of urban and rural residents' ginseng protect school-age. Its purpose is to ease the realistic problem urgently to be solved in urban and rural pension, etc. But, because of the related system in promoting the preliminary stage, the coverage of comprehensive has the value of further research exploring. The differences and the cost of insurance to pay around, some regions where financial support higher proportion of pay is certain difficulty. Considering, urban and rural residents own payment ability was insufficient, plus local fiscal subsidy and easy it is to do enough, some parts of available after retirement fund may be less than one hundred Yuan, this is enough to provide for the aged.

The above these problems have brought certain difficulty for urban and rural development, but also they are a great addition to promote the development of low carbon insurance and effective driving force.

\section{The problems facing development}

\subsection{Urban and Rural Insurance Market Failure}

The externality of insurance and market information asymmetry makes the urban and rural insurance market susceptible to market failure. In terms of externality, the insurance itself already has the characteristics of externalities. As agricultural insurance of quasi-public goods, it has externality characteristics, and also its own interest features. Agricultural insurance is a kind of high cost, insurance compensation than the major. In an insurance company, it does this commitment at the same time protect the interests of their own company. Under the condition of agricultural risks, the related products will inevitably produce supply. This leads to the inevitable is agricultural insurance ginseng protect personnel to the private marginal cost is too high, more than the marginal cost of the society. Eventually making the effective demand of agricultural insurance products is lower than the actual supply, balance between supply and demand of agricultural insurance market difficult to achieve.

\subsection{The Acceptance for Low Carbon Insurance too Low}

A long time in vulgar business development mode makes the farmers pay more attention to immediate interests. Farmers for the future benefits and risks the lack of a more macro comprehensive control. There is a huge fluky psychology, they often don't want to use their money to invest in can't timely income or no income of insurance products, especially the new insurance products. And low carbon insurance is a new concept, most of the farmers of the concept, and little, some even know nothing about. In this case, how do we take measures as soon as possible let need ginseng protect farmers understand and accept, is now low carbon insurance to promote the biggest problem facing in the process.

\section{3. insurance companies lack of confidence}

In such cases, the investment enthusiasm of insurance company is a big blow. Low carbon insurance relatively large initial investment, but the market situation is not clear, the future development has many uncertain factors, and the reality is further reduced in the enthusiasm of the insurance company. Small insurance to insurance company's appeal is insufficient. The government's support is attracting small insurance the insurance company to enter the market advantage. After all possible major investment projects alone about enterprise cash flow problem with insurance company's social responsibility consciousness is not enough.

\section{CONCLUSIONS}

Due to promote low carbon insurance, local governments is the biggest impetus. Only government attaches great importance to the corresponding measures, and provide policy support to accelerate low-carbon insurance in urban and rural areas. The government section should strengthen 
the propaganda of the low carbon insurance benefits to farmers and guide farmers to understand step by step. In addition, the government also needs to provide support on the policy of low carbon insurance, ease restrictions on the development of insurance companies in the market, as far as possible to give the insurance company within the range ability of low carbon insurance project is certain incentives and subsidies. To promote the urban and rural change idea as soon as possible, protect the interests of urban and rural. In terms of the insurance company, it should consciously to shoulder more social responsibilities, the corresponding basic responsibilities. , the insurance company shall actively pay close attention to changes in urban and rural areas and agricultural and sideline products market, thus to better cope with the present situation of innovation to develop suitable for urban and rural insurance products. Insurance companies need to do our best to adjust the product structure and related expenses composition proportion, while meet the development of low carbon insurance, guarantee their basic interests.

As a low carbon insurance implementation main body of the farmers is the center of all the work, but it is also the difficult point in all work. We can do is just trying to get farmers to renew the idea, trust in government and subject to agricultural insurance.

\section{Acknowledgements}

The research work was supported by Baoding city Science and Technology Bureau under Grant No. 15ZR017 and 2014 Annual Research Fund Project of HeBei Finance University under Grant NO.JY201406 .

\section{Reference}

[1] Zuoxiong Zhang, "Agricultural Insurance Business Model Selection and Development of Ideas in Jiangsu Provence," Proc. China Insurance, pp. 2010(2).

[2] Heaton J B.Managerial, "Optimism and Corporate Finance," Proc. Financial Management, pp. 33-45, 2002.
[3] Malmendier U, Tate G, "Overconfidence and Corporate Investment," Proc. Journal of Finance, pp. 2661-2700, 2005.

[4] Wei Chen, "Research on the innovation development mode of low carbon insurance in the rural," Proc. Journal of Jiangxi Finance College, pp. 62-67, 2010.

[5] Yuhuan Liu, Changyue Li, "The market survey report about how to develop small insurance," Proc. Rural Finance Research, pp. 34-38, 2010. 